\title{
Aneurysm of pulmonary artery with persistent ductus arteriosus and pulmonary infundibular stenosis Fatal dissection and rupture in pregnancy
}

\author{
P. G. D'Arbela, J. W. Mugerwa, A. K. Patel, and K. Somers ${ }^{1,2}$ \\ From the Departments of Cardiology and Pathology, Makerere University Medical School, \\ P.O. Box 7072, Kampala, Uganda
}

A case of aneurysm of the pulmonary artery in a young pregnant woman is described. In addition, she had a persistent ductus arteriosus and congenital right ventricular infundibular muscular stenosis. At necropsy the wall of the pulmonary artery showed lesions of medionecrosis.

Death occurred in relation to evacuation of the bowels. Presumably the increased intrathoracic pressure caused the final rupture of the aneurysm, which had probably already dissected extensively.

Aneurysms of the pulmonary artery are rare and may affect the main pulmonary artery or one of the major branches. An association with persistent ductus arteriosus has been noted in 20 per cent of cases (Deterling and Clagett, 1947). Occasionally ligation of a persistent ductus arteriosus may be complicated by the formation of a post-operative aneurysm (Thomas, 1960). Pulmonary aneurysm may also follow infective endocarditis of a persistent ductus arteriosus (Lillian, 1949). Occasionally Marfan's syndrome (Tung and Liebow, 1952; Best, 1967) and long-standing pulmonary hypertension such as that accompanying a large ventricular septal defect (Johannsen and Connor, 1943; Richards and Cohn, 1954) may result in aneurysm of the pulmonary artery.

Aneurysms of the pulmonary artery are liable to rupture into the lung, resulting in fatal haemoptysis, or into the pericardium, with tamponade and sudden death. The diagnosis may be obvious on a straight chest film if considerable dilatation of the pulmonary artery is seen. If not, it may be proved by angiocardiography. Because of the rarity of aneurysm of the pulmonary artery, and because of the association of persistent ductus arteriosus and pulmonary infundibular stenosis in the present instance, we make this case report.

1 In receipt of grants from British Heart Foundation.

2 Requests for reprints to $K$. S.

\section{Case report}

An I8-year-old Ugandan housewife, 28 weeks pregnant, was admitted on 2 May 1968 . She had been under observation for one month at a district hospital, with pulmonary oedema and clinical features of severe pulmonary hypertension. She gave a history of having been somewhat dyspnoeic and also having suffered vague chest pain since childhood.

Examination revealed a well-built young pregnant woman who appeared restless as if from labour pains. She was apyrexial, not anaemic or cyanosed, and had no finger clubbing. The pulse was 85 a minute, regular, not collapsing, the blood pressure being $120 / 80 \mathrm{~mm}$. Hg. The apex beat was located in the fifth left intercostal space in the anterior axillary line: the cardiac impulse was of left ventricular type together with a left parasternal heave. Auscultation revealed a long, grade $4 / 6$, harsh systolic murmur, of ejection type, maximal over the left sternal edge in the third and fourth intercostal space, and associated with a systolic thrill; a high-pitched grade 2/6 early diastolic murmur was also present. The systolic murmur was also heard over the pulmonary area though less loudly, while the pulmonary component of the second sound was soft. There was no ejection click. At the apex there was a grade 2/6 pansystolic murmur radiating to the axilla. This was accompanied by a soft grade 2/6 mid-diastolic rumble and a third heart sound. No abnormality was observed at the aortic area. Coarse crepitations were heard in the lungs. The liver and spleen were not palpable. The fundi were normal. The chest $x$-ray (Fig. I) showed a large heart with a cardio- 


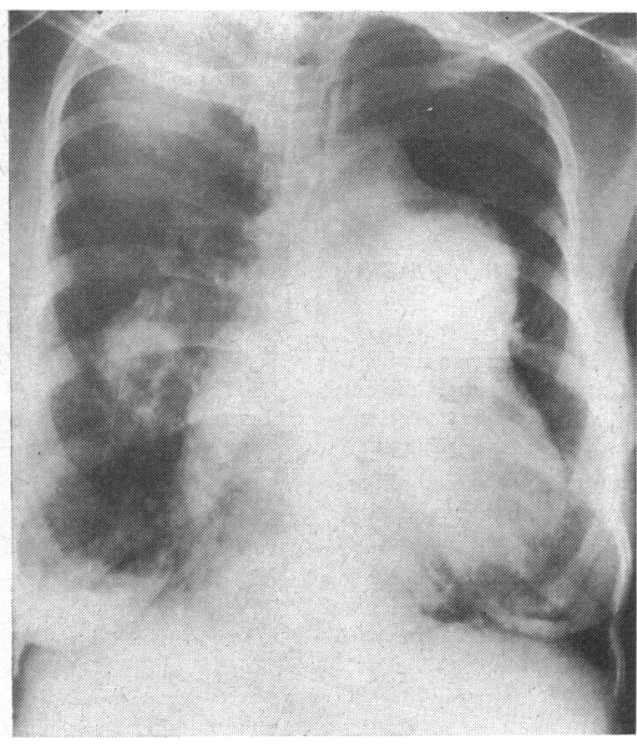

FI G. I Postero-anterior chest $\mathrm{x}-$ ray showing aneurysm of pulmonary artery.

thoracic ratio of 68.5 per cent. There was a huge round shadow overlying the pulmonary area, associated with conspicuous pulmonary oedema. The right ventricle and both atria were enlarged. The electrocardiogram showed ÂQRS of $+100^{\circ}$ in the frontal plane, and the features of right ventricular hypertrophy and incomplete right bundle-branch block. Haemoglobin was II.8 g./100 ml., WBC 3500/cu. mm., erythrocyte sedimentation rate (Westergren) $27 \mathrm{~mm}$. in the first hour.

The patient had been treated by digoxin and diuretics before the referral, and these were continued. The apparent labour pains rapidly settled and she remained in hospital under observation. On I6 May I968, she suddenly became restless again and was groaning continuously. She complained of palpitations and pain over the praecordium, radiating to the left axilla, neck, and back. There were still crepitations in the lungs and she was dyspnoeic and cyanosed. The blood pressure was $130 / 70 \mathrm{~mm}$. $\mathrm{Hg}$. The jugular venous pressure was $4-5 \mathrm{~cm}$. above the sternal angle. The cardiac signs, the chest $x$-ray, and the electrocardiogram were virtually unchanged. No evidence of venous thrombosis in the lower limbs was detectable. Labour pains began later the same day, and the following day she had a spontaneous breech delivery of a macerated foetus.

Two days later, on 18 May 1968, she was very much improved and ambulant and she had recovered from the labour. A further cardiac review was awaited. On 20 May 1968, she was found dead in the lavatory.

Necropsy The pericardial sac was tense and contained $1000 \mathrm{ml}$. blood. The aorta, pulmonary artery, and large veins were normally positioned. There was a large fusiform aneurysm of the pulmonary trunk (Fig. 2), with a small oval rupture about $8 \mathrm{~mm}$. in length communicating with the pericardial sac. On the intimal side of the aneurysm there were several semicircular areas of dissection. The aorta was connected to the main trunk of the pulmonary artery, just before its division, by a persistent ductus arteriosus, which was only a few millimetres in length and measured I cm. in diameter. There were some intimal plaques in the aorta around the opening of the ductus but no evidence of widespread atheroma. The intrapulmonary branches of the pulmonary artery showed plaques of atheroma, though none was present in the main pulmonary trunk.

The heart weighed $500 \mathrm{~g}$., and the pericardium was covered with a thin fibrinous exudate. Both atria were dilated and trabeculated. The right ventricle wall thickness averaged $I \mathrm{~cm} ., 1 \cdot 5 \mathrm{~cm}$., and $\mathrm{I} \cdot 7 \mathrm{~cm}$. at the apex, middle, and infundibular parts, respectively, while the left measured $I \cdot 5$ $\mathrm{cm}$. in the middle. There was no ventricular dilatation. There was a muscular type of stenosis located in the infundibulum of the right ventricle. The tricuspid valve was thickened at its free edge, partly calcified and verrucated, but was neither stenosed nor incompetent. The mitral, pulmonary, and aortic valves were normal in all respects.

The lungs were heavy, firm, and congested. The uterus was bulky, its wall measuring $2 \mathrm{~cm}$. All other organs were macroscopically normal.

FIG. 2 Aneurysm of pulmonary trunk. Note semicircular vent.

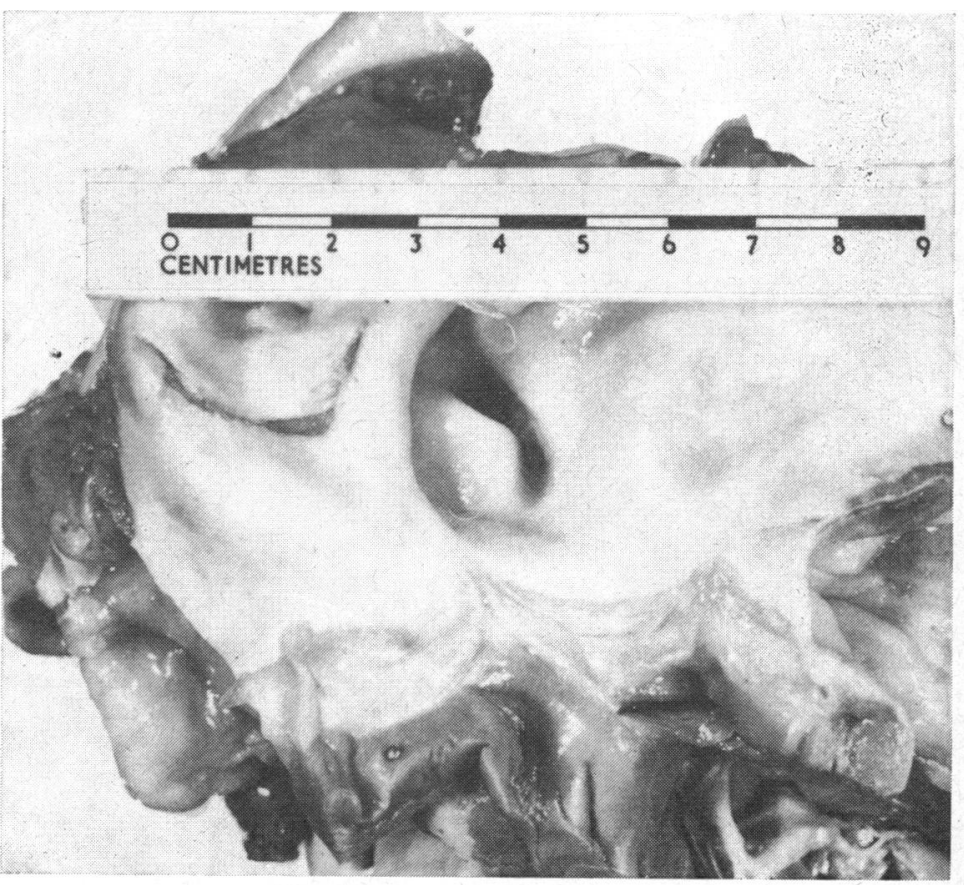


Microscopical examination The pulmonary artery and, to a lesser extent, the aorta, showed pools of mucopolysaccharide in the media, which stained strongly with alcian blue and Mayer's mucicarmine. The changes seen were diffuse in the pulmonary artery and resembled the lesions of aortic medionecrosis. The fragmentation of smooth muscle and elastic fibres was conspicuous in the pulmonary artery but minimal in the aorta. In some sections there was extravasation of blood in the walls of pulmonary artery. Sections of the pulmonary artery showed conspicuous changes due to accumulation of mucopolysaccharide with destruction of the elastica and smooth muscle. Both right and left ventricles showed hypertrophy of the myofibres. Aschoff's lesions were not seen in the ventricle or atria, and there was no evidence of myocarditis. The lungs showed thickened alveolar walls, medial hypertrophy of the pulmonary arterioles, and numerous macrophages laden with haemosiderin.

The cause of death was cardiac tamponade which had resulted from the dissection and rupture of the pulmonary aneurysm.

We are grateful to Professor M. S. R. Hutt, of the Department of Pathology, for helpful advice, and the Department of Medical Illustration, Makerere Medical School, for the photographs. The British Heart Foundation provides recurrent support for our programme in Cardiology.

\section{References}

Best, J. (1967). Dissecting aneurysm of the pulmonary artery with multiple cardio-vascular abnormalities and pulmonary hypertension. Medical fournal of Australia, 2, 1129.

Deterling, R. A., and Clagett, O. T. (1947). Aneurysm of the pulmonary artery: review of the literature and report of a case. American Heart fournal, 34, 471 .

Johannsen, M. W., and Connor, C. A. R. (1943). Cor pulmonale with bilateral aneurysms of the pulmonary artery, interventricular septal defect, patent ductus arteriosus and terminal Ayerza's syndrome. Annals of Internal Medicine, 18, 232.

Lillian, M. (1949). Multiple pulmonary artery aneurysms. Endarteritis of ductus arteriosus and congenital pulmonary cysts. American fournal of Medicine, 7, 280.

Richards, D. W., and Cohn, I. (1954). Interventricular septal defect, pulmonary artery aneurysm with thrombosis, 'cyanose tardive', and paradoxical systemic arterial embolizations. American Heart fournal, 47, 313.

Thomas, D. M. E. (1960). Problems in the surgery of persistent ductus arteriosus. In Modern Trends in Cardiac Surgery, p. 140. Ed. by H. R. S. Harley. Butterworths, London.

Tung, H.-L., and Liebow, A. A. (1952). Marfan's syndrome: observations at necropsy: with special reference to medionecrosis of the great vessels. Laboratory Investigation, 1, 382. 